\title{
Cell Division in genus Corynebacterium: protein-protein interaction and molecular docking of SepF and FtsZ in the understanding of cytokinesis in pathogenic species
}

\author{
ALBERTO F. OLIVEIRA JR ${ }^{1}$, EDSON L. FOLADOR ${ }^{2}$, ANNE C.P. GOMIDE ${ }^{1}$, \\ ARISTÓTELES GOES-NETO ${ }^{3}$, VASCO A.C. AZEVEDO ${ }^{1}$ and ALICE R. WATTAM ${ }^{4}$ \\ ${ }^{1}$ Departamento de Biologia Geral, Laboratório de Genética Celular e Molecular, Universidade Federal de \\ Minas Gerais, Av. Pres. Antônio Carlos, 6627, Pampulha, 31270-901 Belo Horizonte, MG, Brazil \\ ${ }^{2}$ Centro de Biotecnologia/CBiotec, Universidade Federal da Paraíba/UFPB, \\ s/n, Castelo Branco III, 58051-085 João Pessoa, PB, Brazil \\ ${ }^{3}$ Departamento de Microbiologia, Laboratório de Biologia Molecular e Computacional de Fungos, Universidade \\ Federal de Minas Gerais, Av. Pres. Antônio Carlos, 6627, Pampulha, 31270-901 Belo Horizonte, MG, Brazil \\ ${ }^{4}$ Biocomplexity Institute of Virginia Tech, 1015 Life Science Circle, Virginia Tech, 24060, Blacksburg, VA, USA
}

Manuscript received on May 22, 2017; accepted for publication on August 23, 2017

\begin{abstract}
The genus Corynebacterium includes species of great importance in medical, veterinary and biotechnological fields. The genus-specific families (PLfams) from PATRIC have been used to observe conserved proteins associated to all species. Our results showed a large number of conserved proteins that are associated with the cellular division process. Was not observe in our results other proteins like FtsA and ZapA that interact with FtsZ. Our findings point that SepF overlaps the function of this proteins explored by molecular docking, protein-protein interaction and sequence analysis. Transcriptomic analysis showed that these two (Sepf and FtsZ) proteins can be expressed in different conditions together. The work presents novelties on molecules participating in the cell division event, from the interaction of FtsZ and SepF, as new therapeutic targets.
\end{abstract}

Key words: cell division, Corynebacterium, FtsZ, SepF, molecular docking.

\section{INTRODUCTION}

Being currently an important case of public health, pathogenic bacteria are increasingly becoming more and more capable to resisting antibiotics and continue to causing several types of diseases (Fair and Tor 2014, Godziszewska et al. 2016, Doi et al. 2017). New studies aiming to identify potential

Correspondence to: Vasco Ariston de Carvalho Azevedo E-mail: vasco@icb.ufmg.br

* Contribution to the centenary of the Brazilian Academy of Sciences. molecules capable of serving as drug targets have been promising, since they may present new measures in the struggle against infection by these microorganisms. Some of them, as the Corynebacterium genus that includes species of great medical, veterinary and biotechnological importance, and is highly diversified (Dorella et al. 2006), has some specific pathogenic species that are targets of many different studies, for example C. pseudotuberculosis, C. Diphtheria and $C$. ulcerans. Some works aim to stop the manifestation 
of diseases brought by these microorganisms infections (Ott et al. 2010). However, what more enlightening to stop the spread of microorganisms in an infection? Cell division. The cell division process also known as divisome in bacteria of Corynebacterium genus is performed by a complex macromolecular machinery containing more than ten specific and conserved proteins (Donovan and Bramkamp 2014).

Some works about bacterial cell division suggest that the divisome assembly requires the cooperative recruitment of cell division proteins and that this assembly is initiated by the highly conserved Tubulin Homolog FtsZ (Bi and Lutkenhaus 1991a). This stage is proposed to be divided in two steps; (I) Firstly, the early divisome components are responsible for the polymerization of FtsZ into single stranded protofilaments and, (II) secondly, by the late divisome components, which help in the lateral interaction between the protofilaments, forming stable bundles. Some works (Anderson et al. 2004) have observed that FtsZ is presented in a dynamic way, where it is able to interact with many cytosolic molecules. However, in order to the divisome assembly occurs, it is proposed that the Z-ring must be performed in an exact time and to be placed at the moment of the cell division (Donovan and Bramkamp 2014). The aim of this work is to explore the information regarding the identification of the proteins that are present in Corynebacterium species and are directly related to the divisome of bacterial cells.

\section{MATERIALS AND METHODS}

Due to the broad spectrum of infections in both humans and animals and evolutionary factor between the three species previously described, this work used the C. pseudotuberculosis sequences as reference.

SEQUENCE ANALYSIS
The database PATRIC (Davis et al. 2016) is the Bacterial Bioinformatics Resource Center, an information system designed to support the biomedical research community's work on bacterial infections, was used to observe conserved protein family from species. It was done by access the Protein Family Sorter (PFS) tool, which enables to examine the distribution of specific protein families, known as FIGfams, across different genomes. In order to observe the region and how the gene sequences of these proteins are disposed in the genome, the Proteomic Comparison (Overbeek et al. 2014) was used, a tool of protein sequence-based comparison that use bi-directional BLASTP. The annotation of all available bacterial genomes were done by RAST (Aziz et al. 2008) (Rapid Annotation using Subsystems Technology) system. The protein sequence and functional information were also available by access the UniProt knowledgebase (Apweiler et al. 2014) stable, comprehensive, fully classified, richly and accurately annotated protein sequence knowledgebase, with extensive cross-references and querying interfaces. UniProt is comprised of four major components, each optimized for different uses: the UniProt Archive, the UniProt Knowledgebase, the UniProt Reference Clusters and the UniProt Metagenomic and Environmental Sequence Database. A key development at UniProt is the provision of complete, reference and representative proteomes. UniProt is updated and distributed every 4 weeks and can be accessed online for searches or download at http://www. uniprot.org. lu00a9 The Author(s.

\section{IN SILICO PPI NETWORK - THE INTEROLOG MAPPING}

The interolog mapping method, used several times, in various organisms, can be describe as: if two interacting proteins ( $\mathrm{A}^{\prime}$ and $\mathrm{B}$ ') have respective orthologous proteins (A and $\mathrm{B}$ ) in another organism, than the orthologous pair also interacts (Sahu et al. 
2014). This method has been applied to predict the interactions in organisms such as Mycobacterium tuberculosis (Liu et al. 2012), Leishmania spp. (Rezende et al. 2012), and mouse (Lo et al. 2015). This method was validated in previous work in which experimental and curated interactions from DIP database (Xenarios et al. 2000) were utilized as a gold standard and proven to work very well, archiving an area under curve (AUC) of 0.93, a specificity of 0.95 , a sensitivity of at least 0.83 and a precision of 0.99 (Folador et al. 2014). Size and color (light to dark) of the nodes corresponds to the degree of Interaction. Line color (branches) is the STRING score of the interaction (vl_pdbscore column in the supplementary material) on a red/ yellow/green gradient scale. The lowest score is 0.40 (red color) and the highest is 1 (green color). Scores around 0.70 are in yellow color. Here, we used the interolog-mapping method to map orthologous interactions from public databases to nine strains of $C$. pseudotuberculosis biovar ovis. In the propose work, was used a partial interaction network of $C$. pseudotuberculosis of biovar ovis (Folador et al. 2014) and from the total of interaction for this work, a sub-network of the strain $C$. pseudotuberculosis 1002 was used, containing the interaction network for the analyzed proteins (FtsZ, SepF, ClpX and others). The additional file 1 provides the full web interactions while the additional file 2 is the subweb just for the proteins associated with assembly and cell wall. Both can be found at the following link: http://www.lgcm.icb.ufmg.br/alberto/

\section{MOLECULAR DOCKING}

Crystal structure of FtsZ and SepF (PDB id- 1RLU and $3 \mathrm{ZIH}$, respectively) were retrieved from Protein Data Bank (www.rcsb.org). The Table I lists the information about the identity and cover. The PDB structures were submitted to HEX tool (Macindoe et al. 2010). The parameters used for the docking process were correlation Shape+Dars,
TABLE I

Information about the Blast. Alignment between Corynenacterium sequences and Crystal structure from PDB.

\begin{tabular}{cccc}
\hline ID PDB & Query Cover & Identity & E-value \\
\hline 1 RLU & $76 \%$ & $77 \%$ & $1 \mathrm{e}-154$ \\
$3 \mathrm{ZIH}$ & $54 \%$ & $32 \%$ & $8 \mathrm{e}-14$ \\
\hline
\end{tabular}

calculation de-vice-GPU, number of solutions-100, FFT mode -3D fast lite, grid dimension-0.6, receptor range-180, sampling method was Receptor Box, Post processing was Dars Energies, ligand range-180, twist range-360, distance range-40. HEX works on FFT correlation (Chandrajit et al. 2011) using spherical polar coordinates and Gaussian density representation of protein shape. The results were compared based on docking energy with a Etotal -508,45, Eshape -627,82 and Eforce 119,37. The structures were visualized through Pymol (www.pymol.org).

\section{GENE EXPRESSION ANALYSIS}

This analysis was performed as describe in the work (Pinto et al. 2014) published by our research group. The propose work describes the conditions experienced by the bacteria during host infection by sequencing transcripts (RNA-seq) using the $\mathrm{SOLiD}^{\mathrm{TM}} 3$ Plus platform. This analysis was used in order to understand about the simultaneous transcription of specific genes as $f t s Z$ and sepF, which could be associated to work together.

\section{RESULTS AND DISCUSSION}

The PFS results help us to understand what kind of proteins participate in the cell division event. For the early divisome, four family protein were found: FtsZ, FtsK, FtsX and SepF. Some predicted proteins as the regulators for FtsZ, and those belong to the early divisome process, such as ZapA, ZapB, ZapC and ZapD (Donovan and Bramkamp 2014) were not found in our results. For the late divisome, FtsB (DivIC), FtsI (Pbp3), FtsQ and FtsW were 


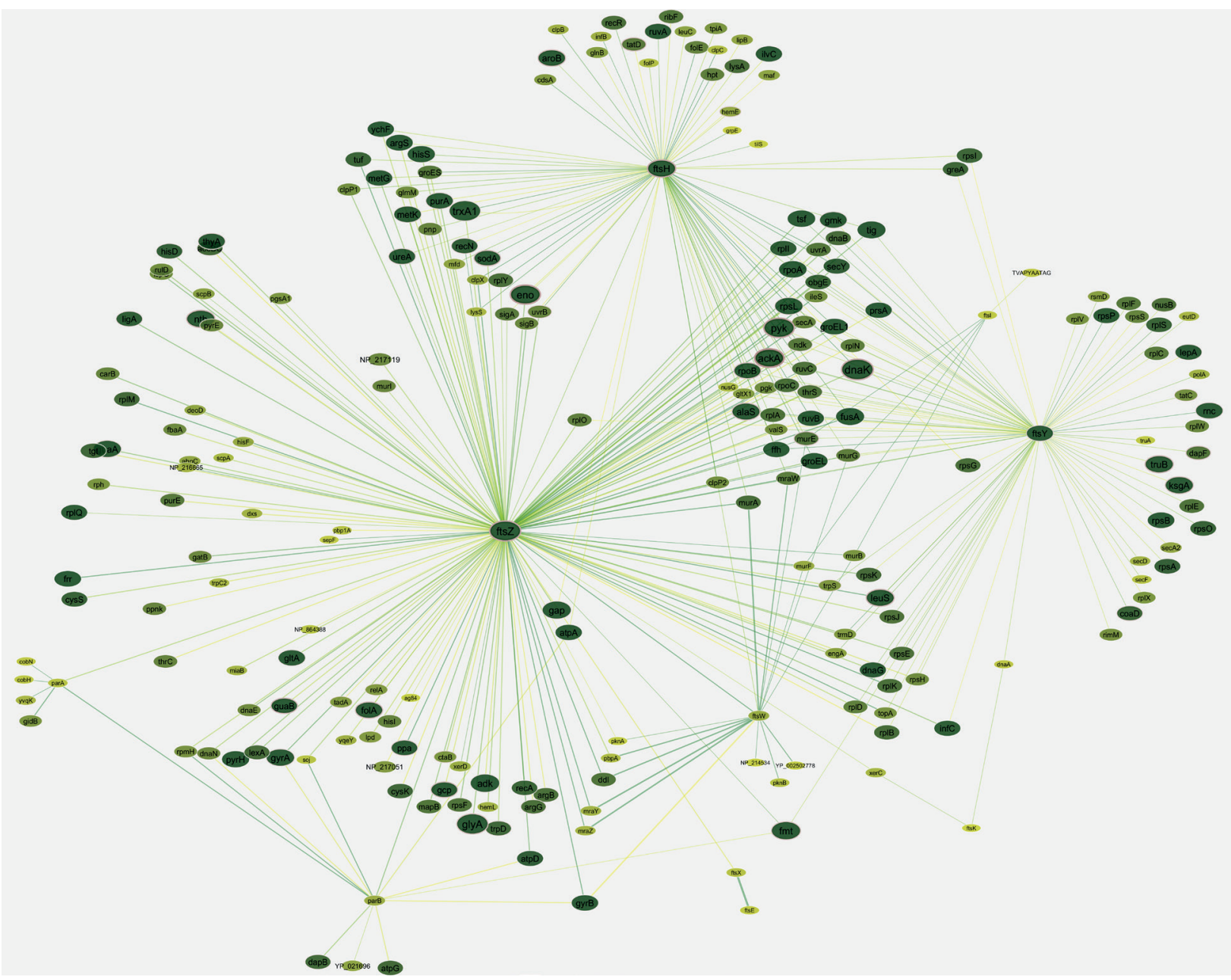

Figure 1 - The protein-protein interaction to cell division proteins of Corynebacterium. The cluster of proteins shows the large number of interactions made by FtsZ with the others fts proteins. In addition, the result shows SepF interacting with FtsZ. In yellow and green ICS $>=0.5625$ (70\% identity for $70 \%$ coverage at least). In red, refers to a lower value, which means less possibility of interaction.

found (Figure S3), with absence of FtsL and FtsN proteins. Some proteins involved in regulation of cytokinesis were also analyzed, and the following ones were found: MinD (ParA), ClpX and DivIVA.

The interactions observed from the PPI results for the cell division, present in more than 100 proteins that are shown in the predicted network (Figure 1), highlight the Filamenting temperature-sensitive (Fts) protein involved in cell division (Buss et al. 2015, Errington, et al. 2003, Lutkenhaus and Addinall 1997) and the Muramyl ligase (Mur) proteins, responsible for the biosynthesis of peptidoglycans (Zoeiby et al. 2003).
In the cytokinesis process, the FtsZ protein plays a central role in the formation of the cytoplasmic membrane ring constriction and, in the anchoring and recruitment of another protein sets related to the cell division process. As described, the initial step is made by the polymerization of the tubulin homolog protein FtsZ (Bi and Lutkenhaus 1991b) into a ring like structure, termed the Z-ring, forming a cytoskeletal scaffold recruiting other cell division proteins for the early division. There are works showing that FtsZ levels do not oscillate during the cell cycle, which means that the Z-ring assembly must be subjected to regulation (Weart and Levin 
2003). A conserved protein, called ClpX has been shown to interact with FtsZ, consecutively, modulating the cell division. Some papers described that this protein is able to play a role as a chaperone, inhibiting Z-ring formation in an ATP hydrolysis (Weart et al. 2005). Other studies described it as a protein able to modulate FtsZ either through degradation of the FtsZ monomers and polymers (Camberg et al. 2009) or by disassembling its polymers (Sugimoto et al. 2010). We expect that ClpX also play when there is any DNA damage, since it is not expected that the mother cell share errors in the DNA sequence to daughter cells. Some evidences suggest that FtsA, by ZipA, is able to interact with and tether FtsZ rings to the membrane (Pichoff et al. 2012), starting the FtsZ ring formation and, thus, promoting the cell division process. However, some works show that SepF (YlmF) sequences are conserved in bacteria with absent to FtsA and ZipA sequences, and this protein has been demonstrated to be essential for cellular growth in Synechococcus elongates (Miyagishima et al. 2005),

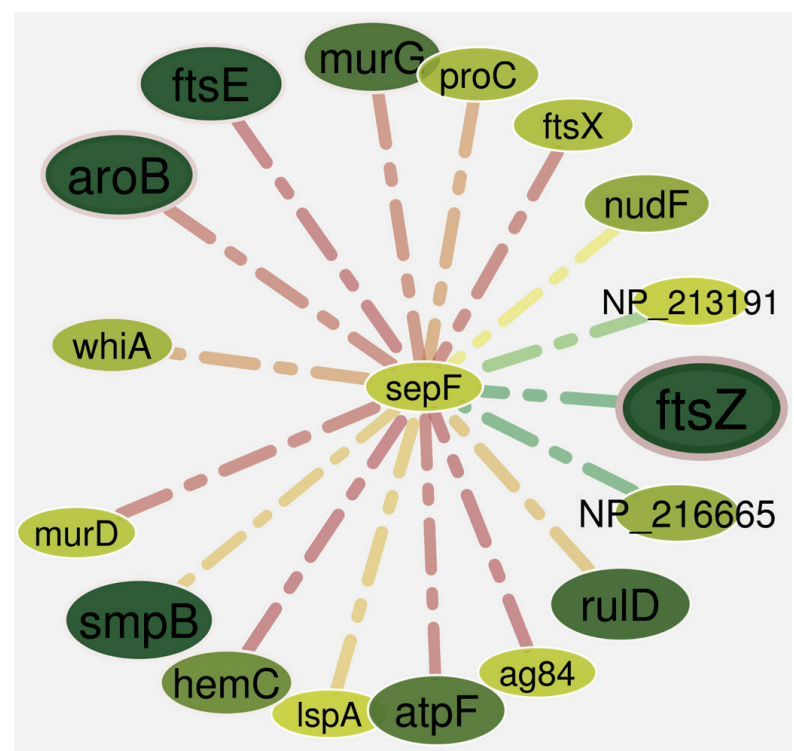

Figure 2 - Sub web to SepF and FtsZ. The sub web to SepF shows the strong interaction between this protein with FtsZ. Looking on the supplementary material at column vl_pdbscore, the value is more than 0.9 , which corresponds to a score based on experimental results.
TABLE II

Amino acid relationship between interaction SepF and FtsZ.

\begin{tabular}{cccc}
\hline $\begin{array}{c}\text { Amino acid of } \\
\text { Ligant (3ZIH) }\end{array}$ & $\begin{array}{c}\text { Amino acid of } \\
\text { Receptor(1RLU) }\end{array}$ & Distance & Chain \\
\hline Lys41 & Asp44 & $1.7 \AA$ & A \\
Lys41 & Met42 & $3.2 \AA$ & A \\
Arg89 & Glu471 & $3.5 \AA$ & B \\
Glu93 & Arg515 & $2.3 \AA$ & B \\
Glu96 & Arg515 & $2.1 \AA$ & B \\
Glu96 & Glu588 & $1.8 \AA$ & B \\
His100 & Asp583 & $3.2 \AA$ & B \\
Gly77 & Asp582 & $3.3 \AA$ & B \\
Thr78 & Ser584 & $2.5 \AA$ & B \\
Ser76 & Asp583 & $3.1 \AA$ & B \\
\hline
\end{tabular}

suggesting a functional relationship between FtsA and SepF. Our results did not show the presence of FtsA in Corynebacterium species, and only the SepF protein was found. One work (Ishikawa et al. 2006) suggested that SepF presents a critical role in cell division in FtsA-lacking bacteria (Ishikawa et al. 2006), where is possible, based in other recent works as well (Gupta et al. 2015), its function overlaps with FtsA. Analysing the sub-web of our ppi results, is clear the SepF is able to interact with FtsZ (figure 2). Based on our results and the ppi, we can infer this is a strong interaction due to the score value to be 0.96 . In order to observe other ways to confirm these interactions between SepF and FtsZ, we made the in-silico protein-protein interaction by molecular docking. SepF structure is represented by 3 ZIH and FtsZ 1RLU, both from PDB data base (Bernstein et al. 1978). Our results showed 10 interactions (Figure 2) between the amino acids from the two proteins, showed in Table II.

The interaction scheme (Figure 3 ) between the proteins shows the chains B from both proteins are able to interact and most of the interactions occur between these two segments. Further, it is possible to view a significant number of positively charged amino acid (Lysine, Arginine and Histidine) interacting with negatively charged amino acid 


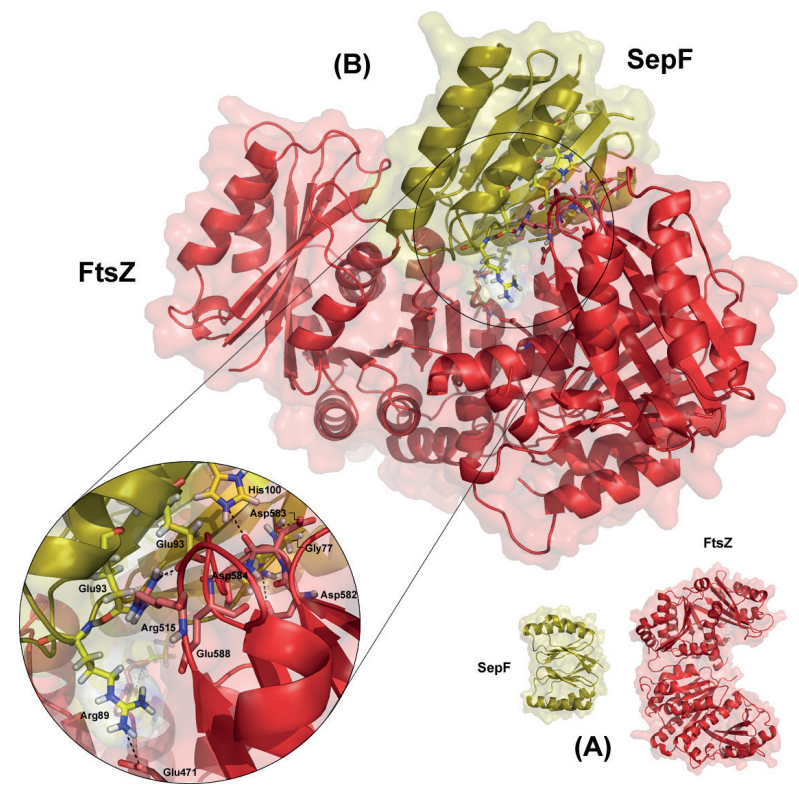

Figure 3 - Protein-Protein docking of FstZ and SepF. (A) The proteins structures before the docking process. (B) The in-silico docking from FtsZ (1RLU) and SepF (3ZIH) highlighting the amino acids involved in the interaction.

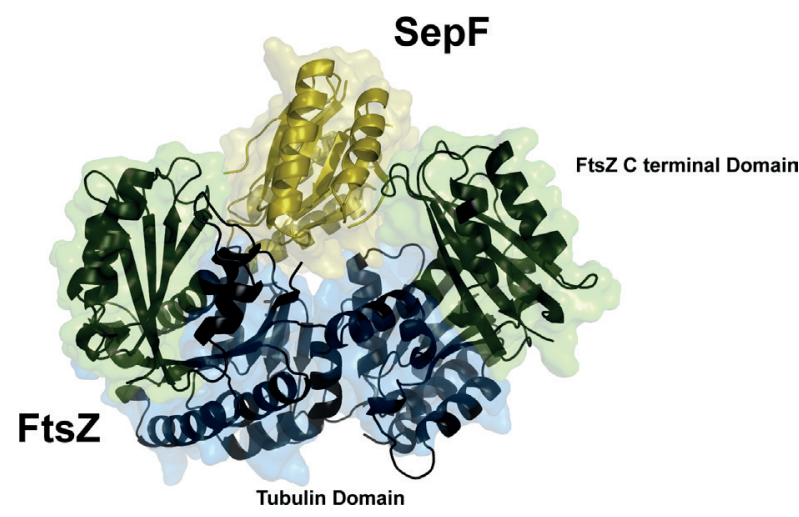

Figure 4 - Scheme that represents the interaction of SepF protein with the domains of FtsZ. Tubulin domain represented by blue color and $\mathrm{C}$-terminal domain represented by green color.

(Glutamic acid and Aspartate acid). It is possible to observe that the interaction happens in the slit of FtsZ strucuture.

In addition, it was possible to understand about the domains that interact with SepF. The tubulin domain that is found in all tubulin chains, as well as in the bacterial FtsZ family of proteins, and the C-terminal domain that is involved in polymer formation were analyzed in the structure.
Our results indicated that the interaction between SepF and FtsZ happens with both 'domains like' as represented in figure 4.

FtsK is described as having an important role when some portions of the chromosome become trapped, forming homohexamers around DNA (Besprozvannaya and Burton 2014), on the wrong side of the division septum. When it happens, segregation at the division plane requires the aid of FtsK translocase, which translocates DNA into the correct cellular compartment. Some works have suggested that FtsB and FtsL (not observed in our results) have a structural role in the assembly of the divisome and they are able to form a higherorder oligomer (Gonzalez and Beckwith 2009, Robichon et al. 2011). However, the specific role of FtsB and FtsL are still not well understood. FtsW and FtsL (pbp3) are described to be associated, and are precursors of recruitment molecules for peptidoglycan synthesis (Mohammadi et al. 2011). It is worth noting the role of FtsW protein in nascent peptidoglycan transport to the outside of the plasma membrane. In the network, we could observe the presence of the proteins encoded by $\operatorname{par} A, \operatorname{par} B$ and $s m c$ genes related to the chromosome partitioning process; Soj with ATPase activity and ScpA related to the condensation process; and the bacterial chromosome segregation during cytokinesis. The PPI results showed that FtsQ is able to connect with all these proteins (Fts) suggesting that it is a central protein in this step. In the network of Corynebacterium genus cell wall formation, these enzymes are mainly represented by MurABCDEFGI and mraY proteins, which are related to the synthesis of new multilayer peptidoglycans cell wall (Vollmer et al. 2008). These proteins mainly interact with FtsZ, showing that FtsZ serves as a support for these proteins to perform their activities accordingly.

Complementary approaches using PPI networks can be of great value to overcome the challenges related to the increasing number 
of resistant pathogenic bacteria to several current therapies. Thus, the organization and the connection between the network elements can help us in the identification and selection of new molecular targets for the development of more effective therapies. Currently, there are several compounds synthesized and directed to act in the inhibition of peptidoglycan synthesis and in cell division steps (Blaauwen et al. 2014). For example, compounds such as Fosfomycin (phosphomycin), 4-thiazolidinone and Phosphinic acid derivatives that act as inhibitors of MurA, MurB and MurCDEF respectively. In this case, the bacteria do not survive by not forming the peptidoglycan layers. Inhibitors directed to block the beginning of cell division by preventing the formation of the constriction ring has been explored and tested against FtsZ, as for example, the sanguinarine inhibitor that, although showing inhibitory activity, is not specific only to the target FtsZ (Blaauwen et al 2014). Therefore, further studies are needed to find more efficient and specific inhibitors and most promising targets against to several bacteria, especially to $C$. pseudotuberculosis, C. diphiteriae, C. ulcerans or any other pathogenic species commonly studied. The protein-protein interaction networks are an important tool for this purpose.

In our protein interaction map, it was not possible to observe the interactions between DivIVA and ParA in Corynebacterium, which is described to involve DNA separation process for the apical region of cell (Ginda et al. 2013). Otherwise, a homolog protein to DivIVA, called Ag84 that has $54 \%$ identity to it, presents interactions in Corynebacterium (Figure S4). In addition, it is possible that ParA interacts with other molecules, and is able to interact with Arg84, being from that, the DNA migration process occurs while daughter cells formation is performed. The interaction map also shows that possibly, while the DNA replication is occurring, the protein ParA is able to interact with DNA polymerase III subunit beta and with other proteins of origin of replication. It is possible that such event occurs in a dynamic way whereas DNA is replicated, since it is already directed towards the apical portion of the cell.

When performing the proteomic comparison, it was possible to observe the sequences of cell division and cell wall formation are close to each other in genome. The sequences of $\arg 84, \mathrm{sepF}, \mathrm{fts} Z$, fts $Q$ appear close to the chomosome, following by two genes that act on cell wall formation murc and $\operatorname{mur} G$, after $f t s W$ forming an operon. In the next, some proteins represented by murABCDEFGI and mraY genes appear ending the operon with $\mathrm{ftsL}$. Thereby, we can suppose that all these sequences are expressed together, as we expected to occur during cytokinesis.

In order to improve the results obtained here, It was performed a C. pseudotuberculosis transcript analysis, reapplied in different environmental conditions. Was able to observe that even in conditions in the transcripts were statistically considered differently express (true), in the control in relation to the various conditions, the fold change value showed up near between the two genes fts $Z$ and $s e p F$. Just in the condition of osmotic control was not considered differently express (false), in relation to the control (Table III). This control infers that possibly the genes fts $Z$ and sepF are transcript together. In the Figure S5, it is observed that the both genes are close (highlighted) which could suggest that they were sharing the same promoter.

In almost all conditions, the fold change value was below one, implying that the genes were repressed relative to the control. Only the sepF gene in the thermal stress condition presented a value slightly above one, which implies that the expression of the gene in relation to the control was practically the same. These results are in agreement with (Jozefczuk et al. 2010), who observed that the organism is usually able to adapt physiologically to a new environment when it reduces its replication, an attempt to survive the stress. 
TABLE III

Information about the gene expression to FtsZ and SpeF.

\begin{tabular}{ccccccc}
\hline Conditions & GeneNames & RPKM 2M & RPKM Control & p-value & $\begin{array}{c}\text { Signature(p- } \\
\text { value }<0,001)\end{array}$ & Fold-change \\
\hline \multirow{2}{*}{$2 \mathrm{M}$} & $\mathrm{ftsZ}$ & 901.88 & 1110.7 & 0.035501526 & FALSE & 0.811992437 \\
& $\mathrm{sepF}$ & 1517.39 & 1565.82 & 0.021039028 & FALSE & 0.969070519 \\
& & & & & \\
$\mathrm{pH}$ & $\mathrm{ftsZ}$ & 514.59 & 1110.7 & $4.20 \mathrm{E}-035$ & $\mathrm{TRUE}$ & 0.463302422 \\
& $\mathrm{sepF}$ & 714.17 & 1565.82 & $9.44 \mathrm{E}-051$ & TRUE & 0.456099679 \\
& & & & & \\
$50^{\circ} \mathrm{C}$ & & & & & & \\
& $\mathrm{ftsZ}$ & 911.37 & 1110.7 & 0.000448776 & TRUE & 0.820536599 \\
& $\mathrm{sepF}$ & 1691.47 & 1565.82 & 0.000708819 & TRUE & 1.080245494 \\
\hline
\end{tabular}

$2 \mathrm{M}$ - means osmotic medium; $\mathrm{pH}$ - acid medium and $50^{\circ} \mathrm{c}$ - heat medium.

\section{CONCLUSIONS}

The proposed work explored information regarding the cell division by conserved proteins in Corynebacterium species, in order to obtain new findings as drug target to pathogenic species. Here, it was not possible to explore the information about the proteins involved in this process without discussing about the cell wall protein, which together make the Cytokinesis process to occur. It was explored how Z-ring filament occurs and how FtsZ - that means to be the main protein associated in this process - can interact with other proteins, specifically SepF. This work showed that Corynebacterium SepF has the same function than FtsA and the set of Zap's proteins, suggesting that these proteins have homologous functions in bacteria. FtsZ has a vast amount of molecular interactions with proteins associated to the membrane, such as FtsQ, FtsW, FtsK and FtsI. As described in E. Coli and B. subitilis, proteins that enable the molecular anchoring of FtsZ to the membrane are FtsA and ZipA. However, such proteins are lacking in Corynebacterium species. We proposed that the FtsZ anchoring to the membrane is due to the interaction with the complex FtsQ-FtsW-FtsK-FtsI. Moreover, in the
Corynebacterium species, the protein DivIVA is represented by Aarg38, which is able to conduct the genetic compartment to the right side on the divisome. In addition, the proposed work identified new proteins candidates as possible drug testing targets, which can be further used to control the manifestation of diseases associated to bacterial infections. Besides the information that was explored in the currently work, we present a set of proteins not usually explored in bacteria to explain the cell division using in silico and in vitro analysis.

\section{ACKNOWLEDGMENTS}

The authors would like to acknowledge the Virginia Polytechnic Institute and Universidade Federal de Minas Gerais for the support in this work. This work was supported by grants from Conselho Nacional de Desenvolvimento Científico e Tecnológico (CNPq) and Coordenação de Aperfeiçoamento de Pessoal de Nível Superior (CAPES), Brazil.

\section{REFERENCES}

ANDERSON DE, GUEIROS-FILHO FJ AND ERICKSON HP. 2004. Assembly Dynamics of FtsZ Rings in Bacillus subtilis and Escherichia coli and Effects of FtsZ-Regulating Proteins. J Bacteriol 186(17): 5775-5781.

APWEILER R ET AL. 2014. Activities at the Universal 
Protein Resource (UniProt). Nucleic Acids Res 42(D1): D191-198.

AZIZ RK ET AL. 2008. The RAST Server: Rapid Annotations using Subsystems Technology. BMC Genomics 9(1): 75.

BERNSTEIN FC, KOETZLE TF, WILLIAMS GJ, MEYER JR EE, BRICE MD, RODGERS JR, KENNARD O AND SHIMANOUCHI MT. 1977. The Protein Data Bank: A Computer-based Archival File For Macromolecular Structures. J Mol Biol 112(3): 535-542.

BESPROZVANNAYA M AND BURTON BM. 2014. Do the same traffic rules apply? Directional chromosome segregation by SpoIIIE and FtsK. Mol Microbiol 93(4): 599-608.

BI EF AND LUTKENHAUS J. 1991 FtsZ ring structure associated with division in Escherichia coli. Nature 354(6349): 161-164.

BUSS J, COLTHARP C, SHTENGEL G, YANG X, HESS H AND XIAO J. 2015. A Multi-layered Protein Network Stabilizes the Escherichia coli FtsZ-ring and Modulates Constriction Dynamics. PLOS Genet 11(4): e1005128.

CAMBERG JL, HOSKINS JR AND WICKNER S. 2009. ClpXP protease degrades the cytoskeletal protein, FtsZ, and modulates FtsZ polymer dynamics. Proc Natl Acad Sci U S A 106(26): 10614-10619.

BAJAJ C, CHOWDHURY R AND SIDDAVANAHALLI V. 2011. F2Dock: Fast Fourier Protein-Protein Docking, IEEE/ACM Trans Comput Biol Bioinform 8(1): 45-58.

DAVIS JJ, GERDES S, OLSEN GJ, OLSON R, PUSCH GD, SHUKLA M, VONSTEIN V, WATTAM AR AND YOO H. 2016. PATtyFams: Protein Families for the Microbial Genomes in the PATRIC Database. Front Microbiol 7(February): 1-12.

DEN BLAAUWEN T, ANDREU JM AND MONASTERIO O. 2014. Bacterial cell division proteins as antibiotic targets. Bioorg Chem 55: 27-38.

DOI Y ET AL. 2017. Gram-Negative Bacterial Infections: Research Priorities, Accomplishments, and Future Directions of the Antibacterial Resistance Leadership Group. Clin Infect Dis 64(suppl. 1): S30-S35.

DONOVAN C AND BRAMKAMP M. 2014. Cell division in Corynebacterineae. Front Microbiol 5(April): 1-16.

DORELLA FA, PACHECO LG, OLIVEIRA SC, MIYOSHI A AND AZEVEDO V. 2006. Corynebacterium pseudotuberculosis: microbiology, biochemical properties, pathogenesis and molecular studies of virulence. Vet Res 37(2): 201-218.

EL ZOEIBY A, SANSCHAGRIN F AND LEVESQUE RC. 2003. Structure and function of the Mur enzymes: Development of novel inhibitors. Mol Microbiol 47(1): $1-12$.

ERRINGTON J, DANIEL RA AND SCHEFFERS DJ. 2003. Cytokinesis in bacteria. MMBR 67(1): 52-65.

FAIR RJ AND TOR Y. 2014. Antibiotics and bacterial resistance in the $21^{\text {st }}$ century. Perspect Med Chem 6: 25-64. FOLADOR EL, HASSAN SS, LEMKE N, BARH D, SILVA A, FERREIRA RS AND AZEVEDO V. 2014. An improved interolog mapping-based computational prediction of protein-protein interactions with increased network coverage. Integr Biol 6(11): 1080-1087.

GINDA K, BEZULSKA M, ZIÓŁKIEWICZ M, DZIADEK J, ZAKRZEWSKA-CZERWIŃSKA J AND JAKIMOWICZ D. 2013. ParA of Mycobacterium smegmatis co-ordinates chromosome segregation with the cell cycle and interacts with the polar growth determinant DivIVA. Mol Microbiol 87(5): 998-1012.

GODZISZEWSKA J, GUZEK D, GLABSKI K AND WIERZBICKA A. 2016. Mobile antibiotic resistance the spread of genes determining the resistance of bacteria through food products. Postepy Hig Med Dosw 70(0): 803-810.

GONZALEZ MD AND BECKWITH J. 2009. Divisome under construction: Distinct domains of the small membrane protein $\mathrm{ftsb}$ are necessary for interaction with multiple cell division proteins. J Bacteriol 191(8): 2815-2825.

GUPTA S, BANERJEE SK, CHATTERJEE A, SHARMAAK, KUNDU M AND BASU J. 2015. The essential protein SepF of mycobacteria interacts with FtsZ and MurG to regulate cell growth and division. Microbiol 161(8): 16271638.

ISHIKAWA S, KAWAI Y, HIRAMATSU K, KUWANO M AND OGASAWARA N. 2006. A new FtsZ-interacting protein, YlmF, complements the activity of FtsA during progression of cell division in Bacillus subtilis. Mol Microbiol 60: 1364-1380.

JOZEFCZUK S, KLIE S, CATCHPOLE G, SZYMANSKI J, CUADROS-INOSTROZA A, STEINHAUSER D, SELBIG J AND WILLMITZER L.. 2010. Metabolomic and transcriptomic stress response of Escherichia coli. Mol Syst Biol 11(6): 364.

LIU Z, WANG J, QIU YQ, LEUNG RKK, ZHANG XS, TSUI SKW AND CHEN L. 2012. Inferring a protein interaction map of Mycobacterium tuberculosis based on sequences and interologs. BMC Bioinformatics 13(Suppl 7): S6.

LO Y, HUANG S, LUO Y, LIN C AND YANG J. 2015. Reconstructing Genome-Wide Protein - Protein Interaction Networks Using Multiple Strategies with Homologous Mapping. PLoS One 10(1): e0116347.

LUTKENHAUS J AND ADDINALL SG. 1997. Bacterial Cell Division and the Z Ring. Ann Rev Biochem 66(1): 93-116.

MACINDOE G, MAVRIDIS L, VENKATRAMAN V, DEVIGNES M AND RITCHIE DW. 2010. HexServer: an FFT-based protein docking server powered by graphics processors. Nucleic Acids Res 38(Web Server): W445-W449.

MIYAGISHIMA S, WOLK CP AND OSTERYOUNG KW. 2005. Identification of cyanobacterial cell division genes 
by comparative and mutational analyses. Mol Microbiol 56(1): 126-143.

MOHAMMADI T, VAN DAM V, SIJBRANDI R, VERNET T, ZAPUN A, BOUHSS A, DIEPEVEEN-DE BRUIN M, NGUYEN-DISTÈCHE M, DE KRUIJFF B AND BREUKINK E. 2011. Identification of FtsW as a transporter of lipid-linked cell wall precursors across the membrane. EMBO J 30(8): 1425-1432.

OVERBEEK R ET AL. 2014. The SEED and the Rapid Annotation of microbial genomes using Subsystems Technology (RAST). Nucleic Acids Res 42(D1): D206-D214.

PICHOFF S, SHEN B, SULLIVAN B AND LUTKENHAUS J. 2012. FtsA mutants impaired for self-interaction bypass ZipA suggesting a model in which FtsAs self-interaction competes with its ability to recruit downstream division proteins. Mol Microbiol 83(1): 151-167.

PINTO AC ET AL. 2014. Differential transcriptional profile of Corynebacterium pseudotuberculosis in response to abiotic stresses. BMC Genomics 15(1): 14.

REZENDE AM, FOLADOR EL, RESENDE DM AND RUIZ JC. 2012. Computational Prediction of Protein-Protein Interactions in Leishmania Predicted Proteomes. PLoS One 7(12): e51304

ROBICHON C, KARIMOVA G, BECKWITH J AND
LADANT D. 2011. Role of leucine zipper motifs in association of the Escherichia coli cell division proteins FtsL and FtsB. J Bacteriol 193(18): 4988-4992.

SAHU SS, WEIRICK T AND KAUNDAL R. 2014. Predicting genome-scale Arabidopsis- Pseudomonas syringae interactome using domain and interolog-based approaches. BMC Bioinformatics 15(Suppl 11): 1-8.

SUGIMOTO S, YAMANAKA K, NISHIKORI S, MIYAGI A, ANDO T, OGURA T. 2010. AAA+ chaperone ClpX regulates dynamics of prokaryotic cytoskeletal protein FtsZ. J Biol Chem 285(9): 6648-6657.

VOLLMER W, BLANOT D AND DE PEDRO MA. 2008. Peptidoglycan structure and architecture. FEMS Microbiol Rev 32(2): 149-167.

WEART RB, NAKANO S, LANE BE, ZUBER PAND LEVIN PA. 2005. The ClpX chaperone modulates assembly of the tubulin-like protein FtsZ. Mol Microbiol 57(1): 238-249.

WEART RB AND LEVIN PA. 2003. Growth rate-dependent regulation of medial FtsZ ring formation. J Bacteriol 185(9): 2826-2834.

XENARIOS I, RICE DW, SALWINSKI L, BARON MK, MARCOTTE EM AND EISENBERG D. 2000. DIP: the Database of Interacting Proteins. Nucleic Acids Res 28(1): 289-291. 